\title{
Asking for equitable buildings
}

Derek Jones

Our built environment is not simply the material stuff from which it is made - it depends entirely on its interaction with people to make it meaningful. Lefebvre considered space to be a continual construction of a society (Lefebvre, 1991); Weisman demonstrates that architecture is a cultural artefact (Weisman, 1981, 2000); and Rendell that the spaces we use in architecture are "used, occupied and transformed through everyday activities" (Rendell, 2000). Such constructions will necessarily reflect the biases identified elsewhere in this book.

In the architectural profession, only $25 \%$ women (ARB, 2015) and only 1 in 5 women architects would recommend architecture as a career (Tether, 2016). The latest results from the Architects' Journal Women in Architecture Survey (Architects' Journal, 2017) confirm that the glass ceiling is proving to be made of toughened glass. Such imbalances of gender representation in both buildings and the profession itself inevitably lead to imbalances in the design and provision of space and architecture. For Weisman it is clear: "Feminism implies that we fully recognize this environmental inadequacy and proceed to think and act out of that recognition" (Weisman, 1981).

In the spirit of EqualBITE, this extended recipe (banquet?) provides some guidance on how to make space a bit more equitable. Use this as a series of starting considerations whether you are evaluating your own working environment or particularly if you are responsible for procuring space for other people. 


\section{Be utterly and completely universally inclusive from the start.}

Universal design automatically considers asymmetries. Universal design aims to design for the entire human population not some statistically normal standard in that population (Lidwell et al., 2010). This leads to wider inclusion in existing populations and extends the sustainability of use across all populations through time. And remember that the minimum standards are just that: minimum standards. Universal design goes way beyond what are usually the minimum legal requirements. For example, the Roslin Institute at the University of Edinburgh, has a dedicated breast feeding/expression room going beyond what is required or even recommended. This is not simply about putting a chair in the accessible WC (most people don't like to eat their dinner in a toilet...)

Think intersectionally and beyond conditions - people with particular needs are also individuals and very often have intersections with other requirements. By focusing on the issues that arise from individuals' lived experiences, a far greater empathy in design can be achieved instead of medical conditions, focus on the consequences and the experiences of people. For example, instead of considering 'autism', talk with people on the autistic spectrum to find out about the effects of cognitive overload, panic, shifting mental states, fatigue, and identity. Chances are they intersect with many other users - and not only those with a 'condition'. Make this part of an inclusive design process involving users and stakeholders in an organisation - not simply a list of items.

Lots of little, practical ideas make a huge difference. Have a read through the guides in http://universaldesign.ie/BuiltEnvironment/Building-for-Everyone/. For example: providing rest space in stairwells and larger circulation areas; providing sanitary facilities and support appropriate to each gender (not just the minimum standards - ask what people might need); have a clearly communicated and suitable family policy for an estate, school or individual buildings; consider security beyond the building itself (of arriving and leaving work outside normal hours). As before, setting out issues such as these with stakeholders and users is often more effective and inclusive.

\section{Surface bias and break assumptions to generate new ideas.}

Bias and belief checking. Surfacing hidden gender representations of an organisation or design team can be a useful starting point that is easily achieved through planned methods and means. For example, Fraser (2014) outlines a process used by researchers discussing their subject beliefs at the start of a project. This can be extended to any project team considering new space requirements or building by testing the values and attitudes of the team - remember, this process is one of reflection and consideration, not categorisation.

Check your congruence and spatial assignments. As with bias checking, take a look at the assumptions being made about the spaces you are asking for. Are PhD students squashed into a cupboard while that named professor is in a corner office with windows? Out of these groups of people, who is actually in the building more? And when you look at the function names on a plan of your building (e.g. admin office, research office), which genders first come to mind? Surfacing the socio-political congruence we hold between roles and genders can have an impact on how we design and assign space to both roles and genders.

Share the design. Digital prototyping and building information modelling (BIM) can lead to significantly improved collaboration 
and design performance, but only if it is used in particular ways and with particular values applied (Jones \& Dewberry, 2013). One significant advantage it offers in in surfacing 'hidden' assumptions in individual contributor's contributions when these become shared, they become exposed to wider scrutiny. When this is accompanied by a shared attitude of critical thinking and a shared solutiondriven attitude, significantly improved collaboration and inclusion can be achieved.

\section{Ask for values as well as objects}

Shift your perspective and aim beyond problems. Don't simply ask for things you think you can get now - try to consider what your future values might wish to express. For example, when specifying or designing, considering mental health as opposed to mental illness can help shift the attitudes we bring to activities. It's odd that we are good at specifying spaces for analysing our heads when things go 'wrong' but are pretty bad at asking for spaces that support cognitive well-being. In academia we work with our minds so why should we not take this seriously and realise that our physical and mental bodies are one and the same (Damasio, 2006).

It's OK to ask for dreams and conceptions as well as specifications. Instead of asking for a room with 60 lux, why not ask for light that inspires creative thinking? The minimum lighting level is precisely that - the minimum required for functional performance. It says nothing of spatial quality or the values behind the spaces being created. As Robert Venturi famously stated, it is not a case that we have to have 'either or' 'both, and' is possible (Venturi, 1984).

Ask for flexibility and adaptability. One sad thing that accompanies traditional procurement is the myth that the building being designed will last forever or that we have to get it right when we imagine how the building works. But designing for adaption and future change can allow far greater social and political change to take place in an organisation. The traditional ordering of space assumes some anterior (and better) knowledge of what people want and need and it is simply wrong. The best (and most sustainable) architecture is also responsive and adaptive to human needs - both predicted and unimagined.

\section{Process matters more than product}

Design the process as much as the object itself. We do not have to accept existing modes and methods of procurement and we particularly do not have to accept the habits and failures they have consistently brought to public procurement for many decades (e.g. Morrell, 2011; Egan, 1998; Latham, 1994). Reports on procurement of public buildings repeat the same point - the process of designing is far more important than the product. And this process can itself be designed - so recognise this in any appointments or contracts, both in terms of the individuals involved as well as the legal forms themselves.

Consider soft landings, not hard stage gates. Design processes require decisions to be made and how this is done can have a significant impact on the process itself. Hard stage gates are decision points that have to be met with a yes/no before proceeding (e.g. 'Is everything ready for us to start building?'). Mostly, these are very sensible questions but many buildings and spatial services are now procured using only these 'hard' criteria at all stages of the process, making it far less efficient and effective for longer or more complex projects. The soft landings approach in building procurement allows for extended, performance-based approaches to verification of key stages in the procurement process (British Standards Institution, 2013; Sinclair, 2012). The shift in processes and attitudes required also engenders a more inclusive approach within the design team and between them and stakeholders. 
Include people in the process in a valuable way. The other observation made in Latham (1994) and Egan (1998) is that the relationships between stakeholders and professionals matter. Involving people can be difficult because there simply is no such thing as an objective reality when isolated subjectivities are involved (Hastorf \& Cantril, 1954)! But reaching a consensus is not the only reason or goal for collaboration or co-design - think about capturing different stakeholder perspectives for future record or changes; look for opportunities to design in adaption and change; consider other opportunities for spatial (or even organisational) redesign that may be required.

\section{And finally...}

Remember that a building is not a static artefact. It changes, adapts, grows, ... lives.

How an organisation brings its built environment to life through its operation, organisation and use is just as important if not more so than the elements themselves.

Like gender equity, bringing a building to life is a process, not a product. 